Article

\title{
The Influence of CFRP Anchorage on Achieving Sectional Flexural Capacity of Strengthened Concrete Beams
}

\author{
Hayder A. Rasheed ${ }^{1, *}$, Brandon R. Decker ${ }^{2}$, Asad Esmaeily ${ }^{1, \dagger}$, Robert J. Peterman ${ }^{1, \dagger}$ and \\ Hani G. Melhem ${ }^{1, \dagger}$
}

1 Department of Civil Engineering, Kansas State University, Manhattan, KS 66506, USA; E-Mails: asad@ksu.edu (A.E.); bob@ksu.edu (R.J.P.); melhem@ksu.edu (H.G.M.)

2 Penco Engineering, Plainville, KS 67663, USA; E-Mail: brandondecker81@gmail.com

$\dagger$ These authors contributed equally to this work.

* Author to whom correspondence should be addressed; E-Mail: hayder@ksu.edu; Tel.: +1-785-532-1589; Fax: +1-785-532-7717.

Academic Editor: Mahmoud Reda Taha

Received: 17 October 2015 / Accepted: 4 December 2015 / Published: 14 December 2015

\begin{abstract}
This research program is intended to verify the influence of using distributed external U-wrap CFRP anchorage to shift the failure mode from overall debonding to sectional flexural failure for concrete beams externally bonded with CFRP sheets. Premature cover delamination and FRP debonding are predominant failure modes in FRP flexural strengthening that may be delayed or prevented by using FRP anchorage. The present experimental study aims to comparatively prove that proper anchorage of flexural strengthening is anticipated to yield a classical flexural failure by FRP rupture or concrete crushing. Once the cohesion of concrete and/or the adhesion with the FRP is exhausted, the U-wraps are engaged to provide anchorage to the flexural FRP through shear friction. Accordingly, three identical $\mathrm{T}$ beams and three identical rectangular beams were designed and constructed to examine the capacity improvement by preventing premature debonding failure. The first specimen in each series was tested as a control beam. The second specimen in each series was strengthened using five layers of flexural CFRP in order to admit a debonding failure. The third specimen in each series was strengthened with the same five layers of flexural CFRP plus additional transverse CFRP U-wraps. This study proved that it is possible to quantify the higher flexural capacity of CFRP strengthened beams using external anchorage.
\end{abstract}


Keywords: anchorage system; CFRP sheets; flexural strengthening; reinforced concrete beams

\section{Introduction}

Structural strengthening and repair have become a major topic of interest over the past three decades due to the infrastructural needs for rehabilitation. Externally bonded Fiber Reinforced Polymer (FRP) provides a state-of-the-art technique for strengthening and rehabilitation. Traditional methods of strengthening involve the application of externally bonded steel plates. However, the latter suffers from several shortcomings including the deterioration of bond between the steel and concrete due to steel corrosion, the difficulty in handling large steel plates, and the limited delivery lengths. Composites can provide a strengthening technique where the conventional systems do not work as efficiently. Specifically, FRP sheets can be used in place of steel plates. FRP sheets can be wrapped around a structural element to provide anchorage and ease of construction.

One drawback of the FRP flexural strengthening technique is the dominance of two premature failure modes, namely cover delamination and sheet debonding. These two modes alter the more classical sectional flexural modes of FRP rupture and concrete crushing. While developing methods to predict cover delamination, several investigators formulated empirical and analytical expressions for that purpose [1-7]. Some of these procedures yielded inconsistent results [5]. It was observed by other researchers that FRP debonding failure is still a dominant failure mode even in beams with FRP sheets extending close to the supports, where the stress concentrations are negligible or even those with end anchorage [8-12]. In this case, induced intermediate shear or flexural crack debonding is predominant. To advance the performance of FRP strengthened beams, other studies focused on various ways to prevent such premature modes of failure, among which using different external end anchorage layouts [11-14]. Recently issues raised by the use of externally bonded FRP sheets include the focus on FRP anchorage to improve the utilization of the material in strengthening of reinforced concrete members $[15,16]$.

The present study is intended to qualify the use of a distributed CFRP anchorage system to control both cover delamination and sheet debonding for beams more prone to those failure modes by virtue of having a considerable number of layers in flexural strengthening. $T$ beams are examined to shift their failure mode to FRP rupture and rectangular beams are tested to shift their failure mode to concrete crushing.

\section{Specimen Design}

\subsection{Beam Geometry}

The beam design was performed using a nonlinear analysis program based on the incremental deformation technique. All of the beams have a length of $4877 \mathrm{~mm}$ with a clear span of $4724 \mathrm{~mm}$. The $\mathrm{T}$ beams have web dimensions of $152 \mathrm{~mm} \times 305 \mathrm{~mm}$ with the depth extending through the flange thickness, Figure 1a. The flange dimensions are $406 \mathrm{~mm}$ width and $102 \mathrm{~mm}$ thickness. The main flexural reinforcement consists of 2 No. 5 bars. The compression steel consists of 4 No. 3 bars to hold the shear reinforcement caging Figure 1a. The ultimate moment capacity of the control $\mathrm{T}$ beam is calculated to be $48.78 \mathrm{kN}-\mathrm{m}$. The rectangular beams have the same $152 \mathrm{~mm} \times 305 \mathrm{~mm}$ cross section, Figure $1 \mathrm{~b}$. The 
main flexural reinforcement is identical to that of the $\mathrm{T}$ section with two No. 3 bars used for the compression steel just to provide a caging framework for the shear reinforcement, Figure $1 \mathrm{~b}$. The ultimate moment capacity of the control rectangular beam is calculated to be $46.20 \mathrm{kN}-\mathrm{m}$, which is almost identical to that of the $\mathrm{T}$ beam. Both the $\mathrm{T}$ and rectangular beams have shear reinforcement consisting of No. 3 stirrups at $127 \mathrm{~mm}$ on center, Figure 1a-b. The complete dimensions of the two beam sections are listed in Table 1. Despite the similar moment capacity of both the $\mathrm{T}$ and rectangular sections, the ultimate moment capacity of the same sections strengthened with five CFRP layers yield different failure modes and different results. This is attributed to the existence of the concrete flange that admits FRP rupture failure mode as opposed to concrete crushing in the case of the rectangular section. Nevertheless, the use of a large number of flexural CFRP layers is expected to lead to a deboning failure in the $\mathrm{T}$ and rectangular beams. It is the aim of this work to develop an anchorage system that shifts the debonding failure back to the FRP rupture failure in case of the T beam and concrete crushing failure in case of the rectangular beam.

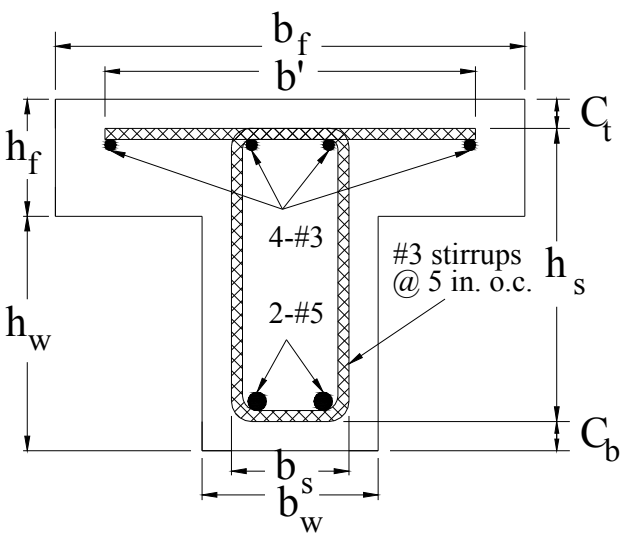

(a)

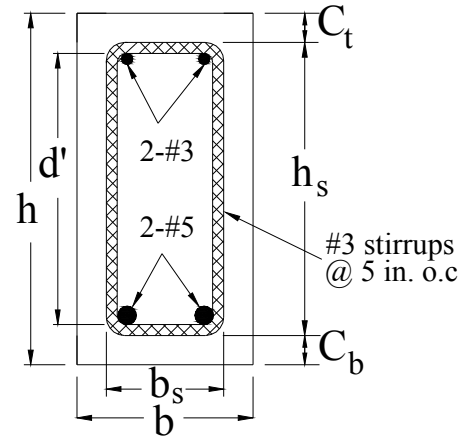

(b)

Figure 1. Beam specimen cross-section (a) T-beam; (b) rectangular beam.

Table 1. Dimensions of beam specimen cross-sections.

\begin{tabular}{cc}
\hline Variable & Dimension \\
\hline$b_{\mathrm{f}}$ & 16 in $(406.4 \mathrm{~mm})$ \\
$h_{\mathrm{f}}$ & 4 in $(101.6 \mathrm{~mm})$ \\
$b_{\mathrm{w}}$ & 6 in $(152.4 \mathrm{~mm})$ \\
$h_{\mathrm{w}}$ & 8 in $(203.2 \mathrm{~mm})$ \\
$C_{\mathrm{t}}$ & 1 in $(25.4 \mathrm{~mm})$ \\
$C_{\mathrm{b}}$ & 1 in $(25.4 \mathrm{~mm})$ \\
$h_{\mathrm{s}}$ & 10 in $(254 \mathrm{~mm})$ \\
$b^{\prime}$ & 13 in $(330.2 \mathrm{~mm})$ \\
$b_{\mathrm{s}}$ & 4 in $(101.6 \mathrm{~mm})$ \\
\hline
\end{tabular}




\subsection{Material Properties}

The concrete that was used in casting the six beams is ready mix with a mix design nominal strength of 34.5 MPa. The average actual compressive strength of 18 test cylinders $(102 \mathrm{~mm} \times 203 \mathrm{~mm})$ was 36.5 MPa. The material properties of the reinforcing steel were provided by the manufacturer to have a modulus of 200,000 MPa and yield strength of $483 \mathrm{MPa}$. The actual tensile testing of three samples of $203 \mathrm{~mm}$ long bar specimens was performed by Kansas Department of Transportation research lab. The average modulus and yield strength of the No. 3 bars were 213,180 MPa and 450.6 MPa, respectively. The average modulus and yield strength of the No. 5 bars were 204,493 MPa and $480.45 \mathrm{MPa}$, respectively.

The material properties of the V-Wrap C100 High Strength Carbon Fiber Reinforced Polymer sheets (CFRP) were provided by the manufacturer to have a modulus of 227,527 MPa, strength of $3792 \mathrm{MPa}$ and sheet thickness of $0.165 \mathrm{~mm}$ based on the net fiber area. This corresponds to an ultimate strain of 0.017. The actual coupon tensile testing was performed based on ASTM Standard D3039. The modulus and strength averaged 59,931.6 $\mathrm{MPa}$ and $768.55 \mathrm{MPa}$ and layer thickness of $0.7 \mathrm{~mm}$ based on the laminate area. These values were the average of five specimens as required by the ASTM Standard corresponding to an ultimate average strain of 0.0129 .

\section{Experimental Program}

\subsection{Test Setup and Data Acquisition}

The flexural tests were performed in the structural testing laboratory of Kansas State University. The beams were loaded in four-point bending using a $1.22-\mathrm{m}$ long steel spreader beam and a $222.5 \mathrm{kN}$ hydraulic actuator. The actuator is controlled by a servo-hydraulic system called FlexTestGT (MTS, Eden Prairie, MN, USA). The beams were simply supported with the supports placed $75 \mathrm{~mm}$ from the edge of the beam, providing a clear span of $4724 \mathrm{~mm}$, see Figure 2. Two-330 mm LVDT devices were placed on each side of the beam at mid-span.

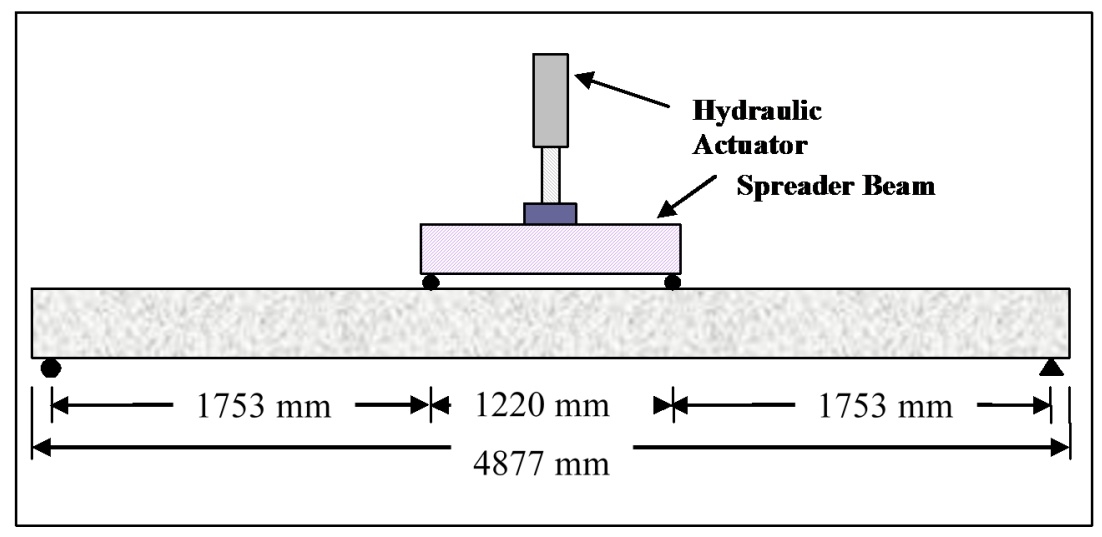

Figure 2. Beam profile and experimental test setup. 


\subsection{Test Results}

\subsubsection{Control T Beam (T1)}

The first specimen tested in the series of T-shaped beams is the control beam (T1). The beam was loaded in load control at a rate of $2.225 \mathrm{kN}$ per minute. At a load of $48.95 \mathrm{kN}$, the system was switched to displacement control at a rate of $2.54 \mathrm{~mm}$ per minute. From the preliminary analysis, the beam was predicted to fail at a load of approximately $54.8 \mathrm{kN}$. Flexural cracks began developing at a load of approximately $19.1 \mathrm{kN}$. The beam failed at a load of $70.75 \mathrm{kN}$. Figure 3 shows beam $\mathrm{T} 1$ at the end of testing. Figure 4 shows the beam load-deflection response to failure. It is evident from Figure 4 that Beam T1 has a post-yield stiffness. This was incorporated in the refined analysis resulting in a failure load of $67.42 \mathrm{kN}$. At the failure load, the deflection of the mid-span was $160 \mathrm{~mm}$ and the failure mode was concrete crushing in the flange at mid span, Figure 3.

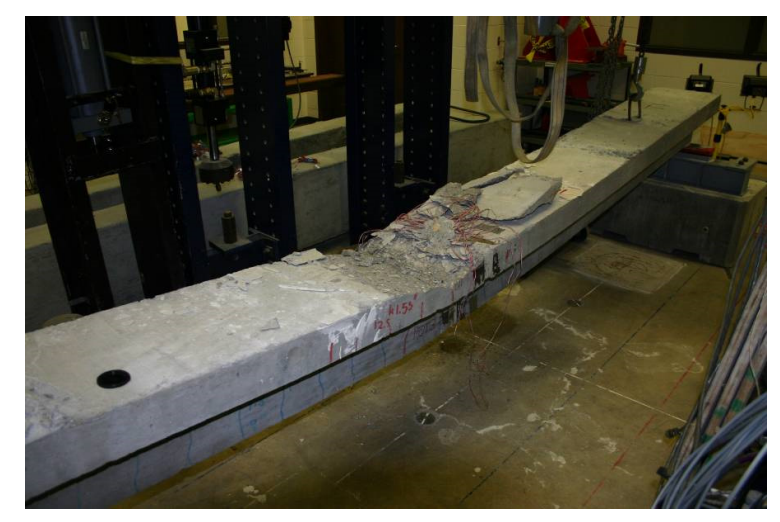

Figure 3. Beam T1 at failure.

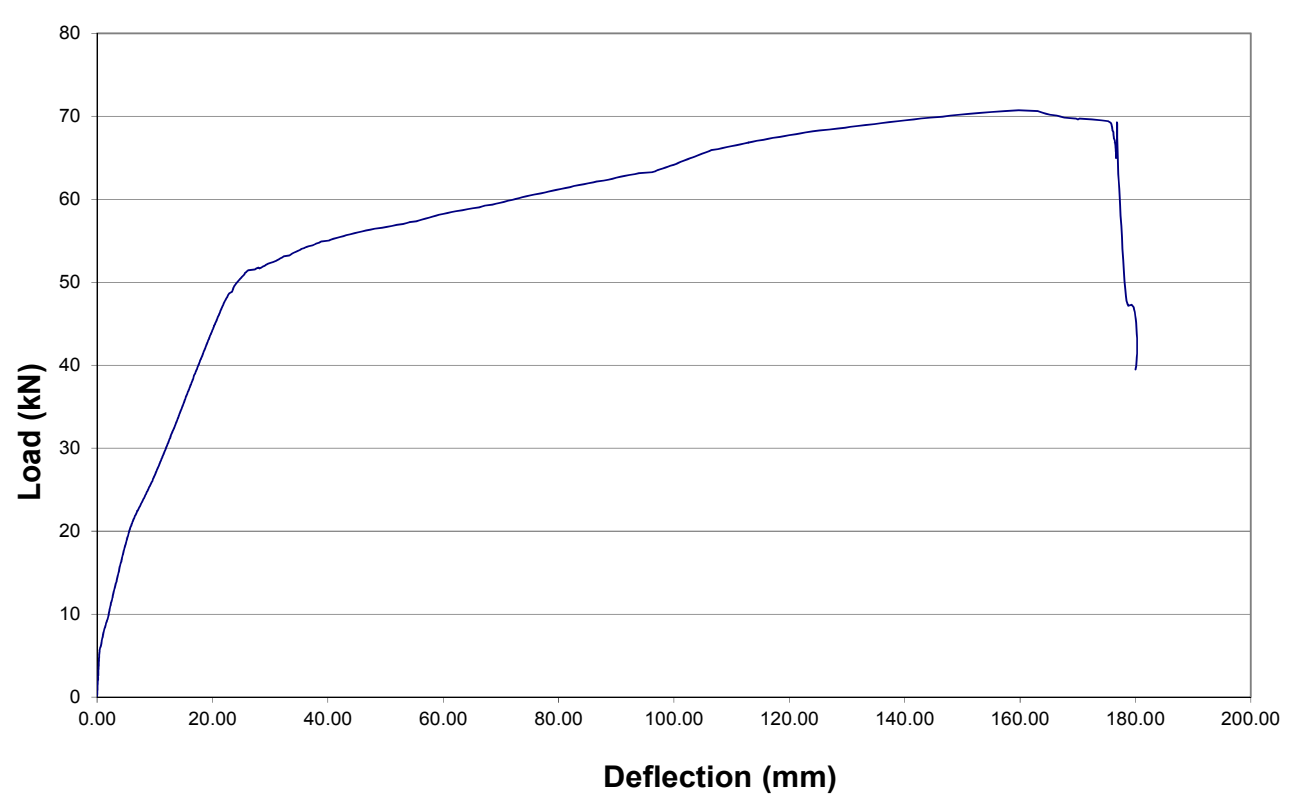

Figure 4. Load-deflection response of T1. 


\subsubsection{T-Beam with Flexural CFRP Only (T2)}

The next beam tested is the T-beam specimen with five layers of flexural CFRP reinforcement on the bottom surface of the beam in the longitudinal direction. For the test to be considered a success, the beam had to fail at a load higher than that of the control beam. Using the Teng et al. [10] model of predicting FRP debonding, it was estimated that the beam would fail at a load of approximately $105.91 \mathrm{kN}$. The beam was loaded in load control at the same load rate of $2.225 \mathrm{kN}$ per minute. At a load of $66.75 \mathrm{kN}$, the control system was switched to displacement control at a rate of $2.54 \mathrm{~mm}$ per minute. The beam reached a load of $113.74 \mathrm{kN}$ when the CFRP debonded with tremendous energy release. This failure load was higher than that predicted by Teng et al. [10] model. At the failure load, the deflection at mid-span was approximately $51 \mathrm{~mm}$ which is much smaller than the $160 \mathrm{~mm}$ deflection of the control beam at peak load. The CFRP detached with mostly debonding failure at the interface while small areas of concrete cover delamination were seen, Figure 5. The load-deflection relationship for this beam specimen is shown in Figure 6.

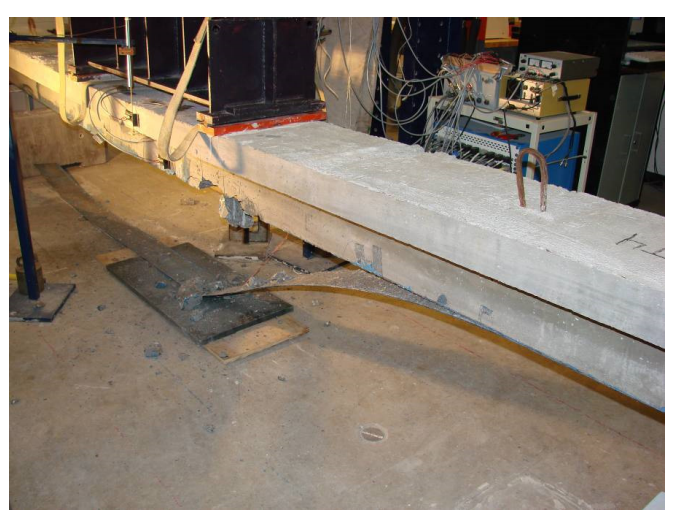

Figure 5. Beam T2 at failure.

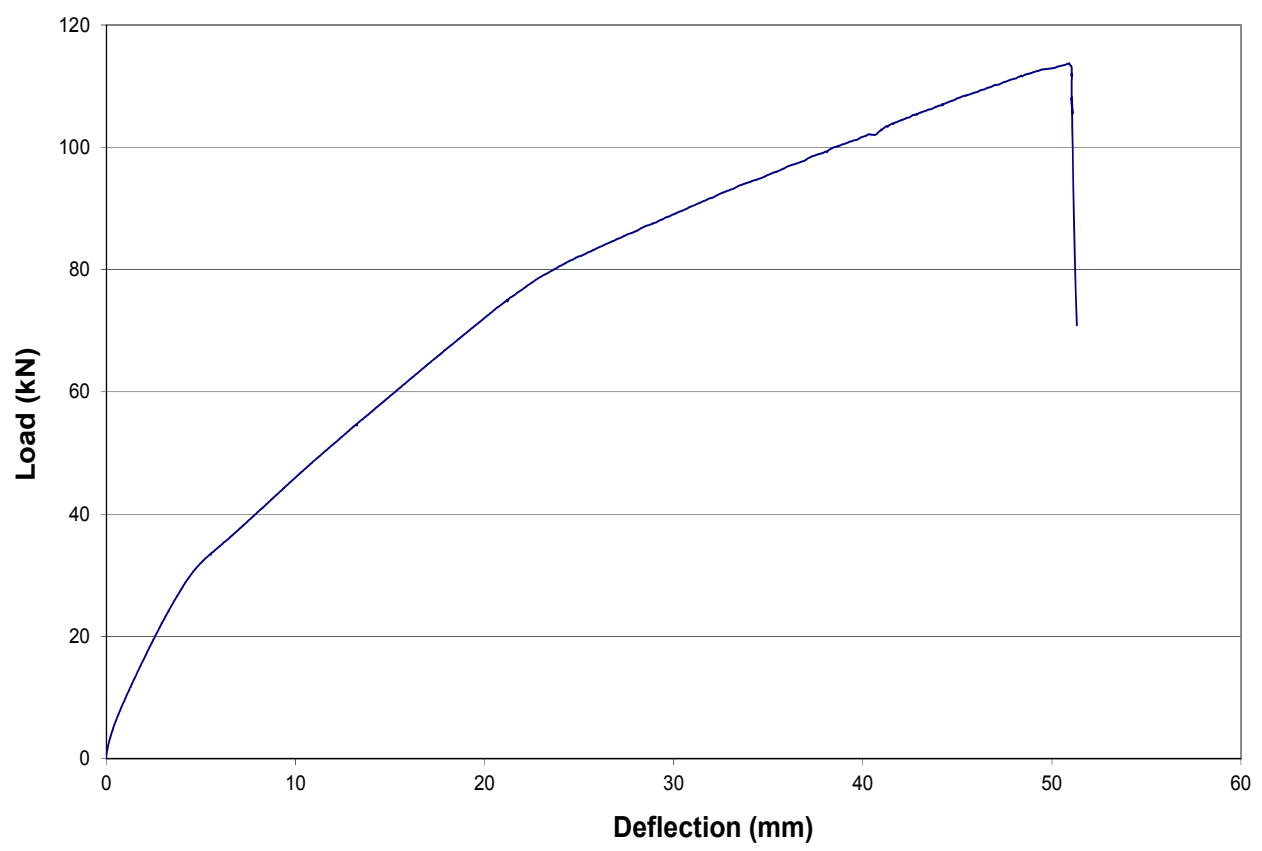

Figure 6. Load-deflection response of $\mathrm{T} 2$. 


\subsubsection{T-Beam with Flexural CFRP and U-Wrap Anchorage (T3)}

The last beam tested in the series of T-beam specimens was strengthened with the same five layers of CFRP on the bottom surface of the web for flexural strength increase and it also had two layers of $127 \mathrm{~mm}$ wide U-shaped wraps around the web spaced at $305 \mathrm{~mm}$ on center. The purpose of these U-wraps was to anchor the bottom layers of CFRP in place as they tend to debond. This beam was loaded at the same rate of the previous specimens (i.e., $2.225 \mathrm{kN}$ per minute). The MTS system was programmed to switch to displacement control at a load of $160 \mathrm{kN}$ based on the preliminary analysis results. At a load of $116 \mathrm{kN}$, about the load at which debonding occurred on beam T2, separation of the flexural CFRP sheets from the beam was evident in between the U-wraps. This was an excellent indication that the U-wraps were performing as they were supposed to by providing resistance to debonding by shear friction. The beam reached an ultimate load of $148.66 \mathrm{kN}$ when the flexural CFRP sheets ruptured at mid-span, as shown in Figure 7. The failure of this beam was more drastic than the previous beams since failure occurred prior to the system switching to displacement control. Figure 8 shows the load-deflection response of beam T3.

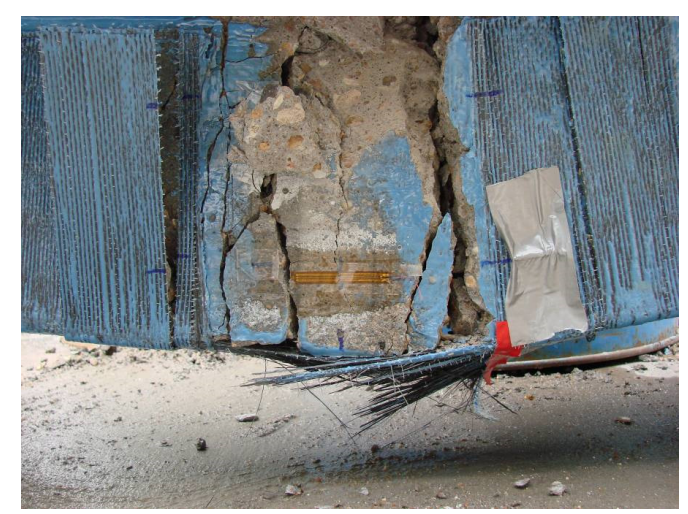

Figure 7. Beam T3 at failure.

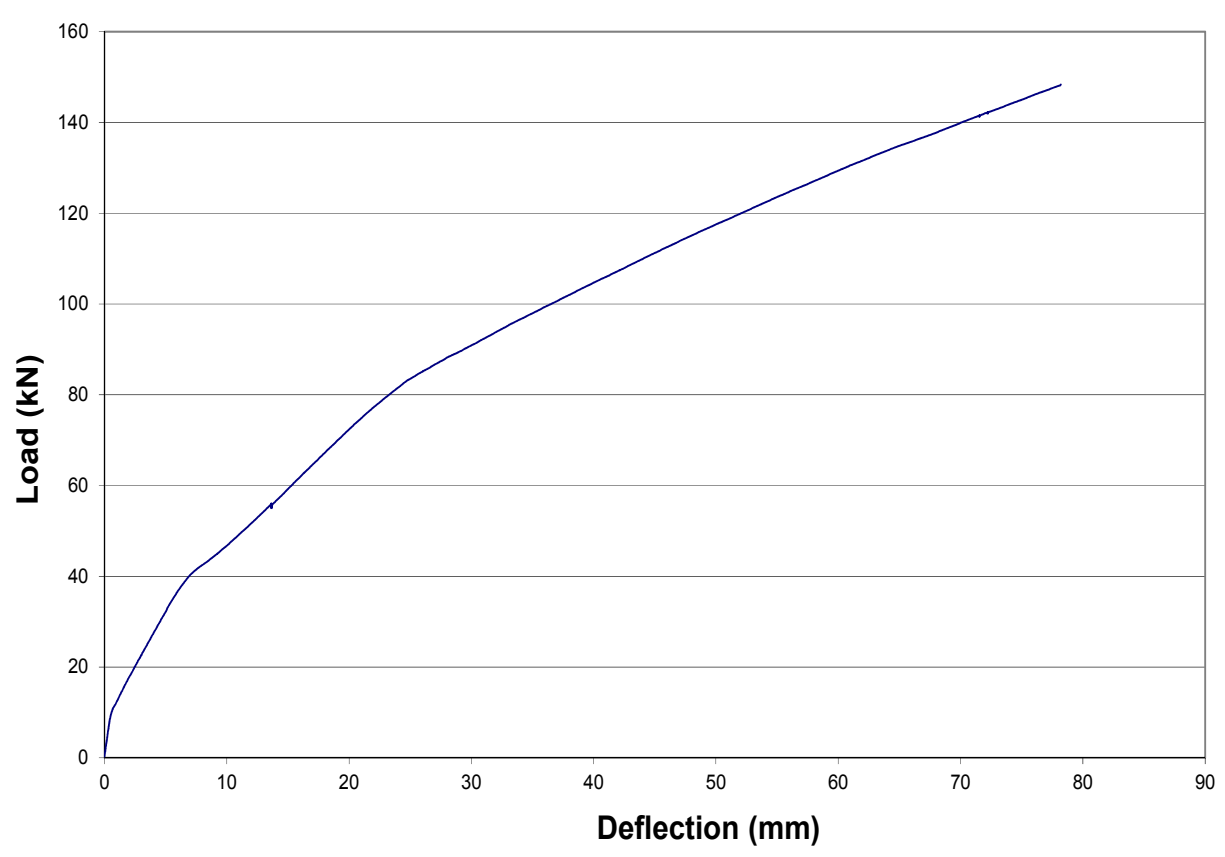

Figure 8. Load-deflection response of T3. 


\subsubsection{Control Rectangular Beam (R1)}

The first beam tested in the series of rectangular beams is the control rectangular beam. It was determined from the flexural analysis program that the beam would fail at a load of $54 \mathrm{kN}$. The beam was loaded in load control at a rate of $2.225 \mathrm{kN}$ per minute. Cracking began taking place at a load of approximately $6.68 \mathrm{kN}$. At a load of $44.5 \mathrm{kN}$, the control system was switched to displacement control to capture the correct peak load. The rate of displacement was $2.54 \mathrm{~mm}$ per minute. The test results show that the beam failed at a load of $54.71 \mathrm{kN}$, which is very close to the theoretical value. The beam failed in a typical mode of steel yielding followed by crushing of concrete. Figure 9 shows beam R1 after failure and Figure 10 presents the load-deflection response of the beam.

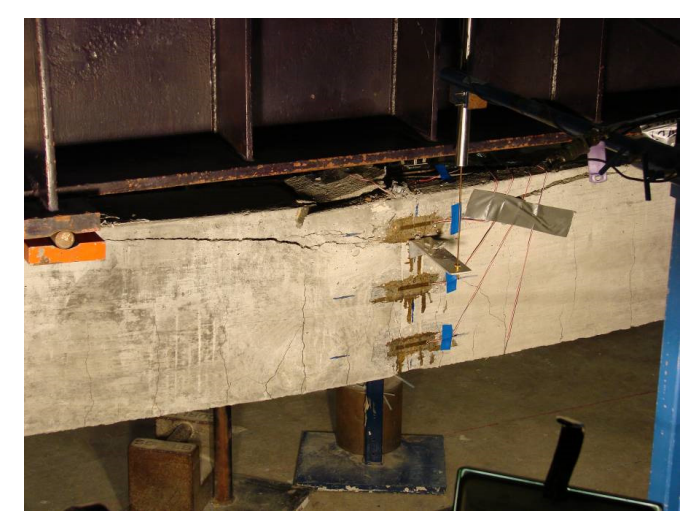

Figure 9. Beam R1 at failure.

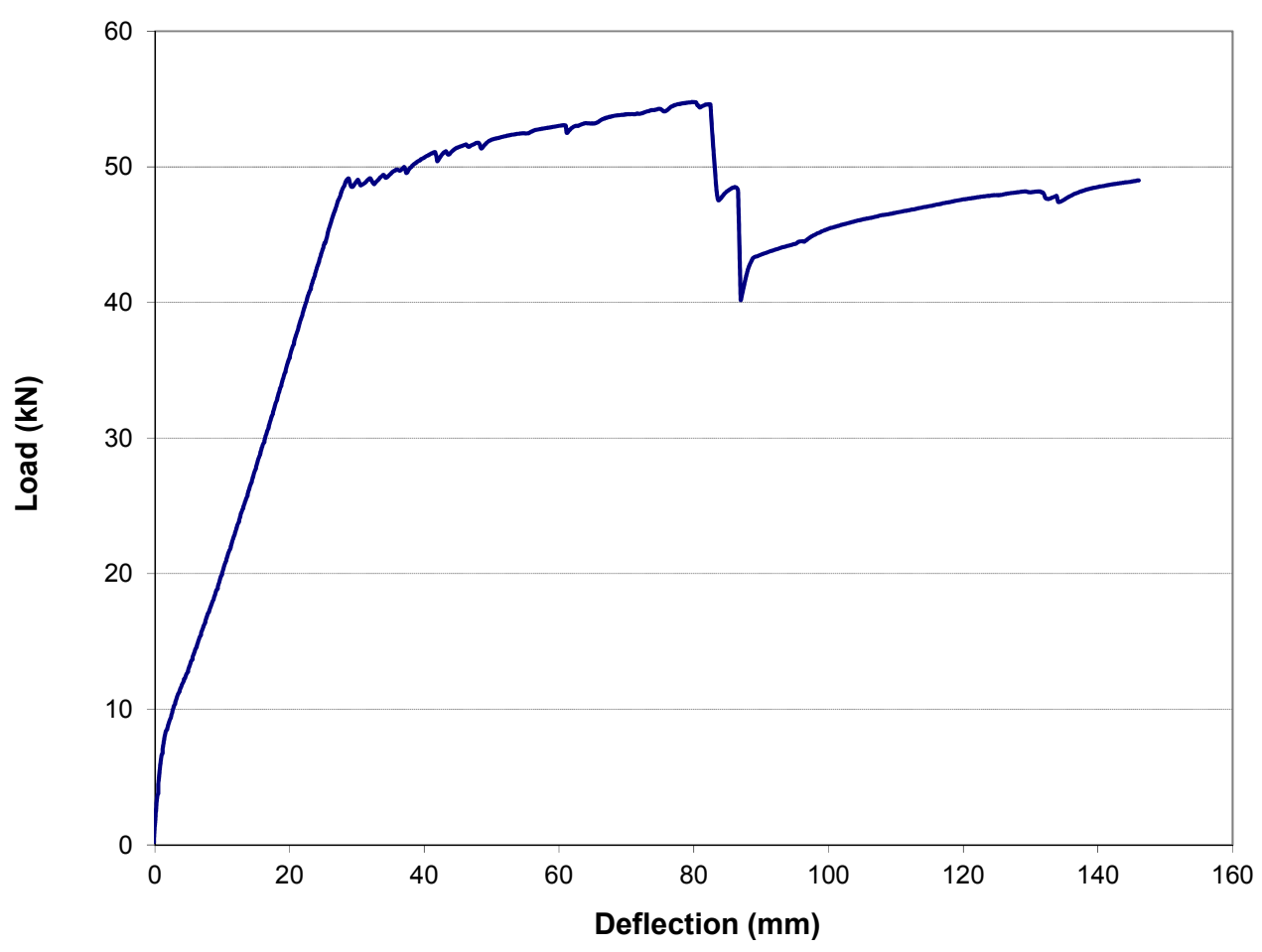

Figure 10. Load-deflection response of R1. 


\subsubsection{Rectangular Beam with CFRP Only (R2)}

The next step was to strengthen the second rectangular beam with five layers of flexural CFRP sheets at the bottom face. For the test to be successful, delamination had to occur at a load higher than that of the control beam, which had an ultimate load of $54.71 \mathrm{kN}$. The CFRP was predicted to debond at a load of $91.23 \mathrm{kN}$ using the Teng et al. [10] debonding equation. The beam was loaded in load control at a rate of $2.225 \mathrm{kN}$ per minute. At $53.4 \mathrm{kN}$, the system was programmed to switch to displacement control at a rate of $2.54 \mathrm{~mm}$ per minute. The load went well past that of the control beam. At a load of approximately $89 \mathrm{kN}$, a lot of popping sounds started coming from the FRP which indicated the occurrence of local debonding. At a load of $109.55 \mathrm{kN}$, the CFRP reinforcement debonded/delaminated with tremendous energy release. This load was higher than that predicted by Teng et al. [10] model, determined to be $102.84 \mathrm{kN}$, indicating a slightly conservative model in this case. The failure mode was mostly debonding failure between the CFRP and the concrete substrate as indicated by Figure 11. However, there were two small locations where the entire cover delaminated. Figure 12 shows the load-deflection results from this beam test.

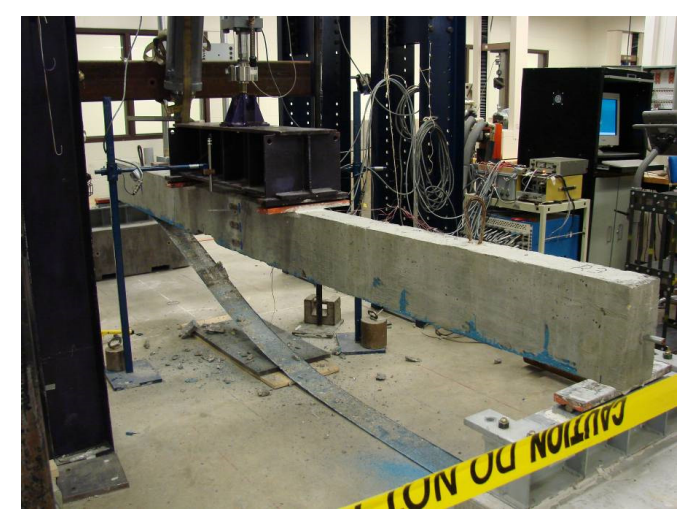

Figure 11. Beam R2 at failure.

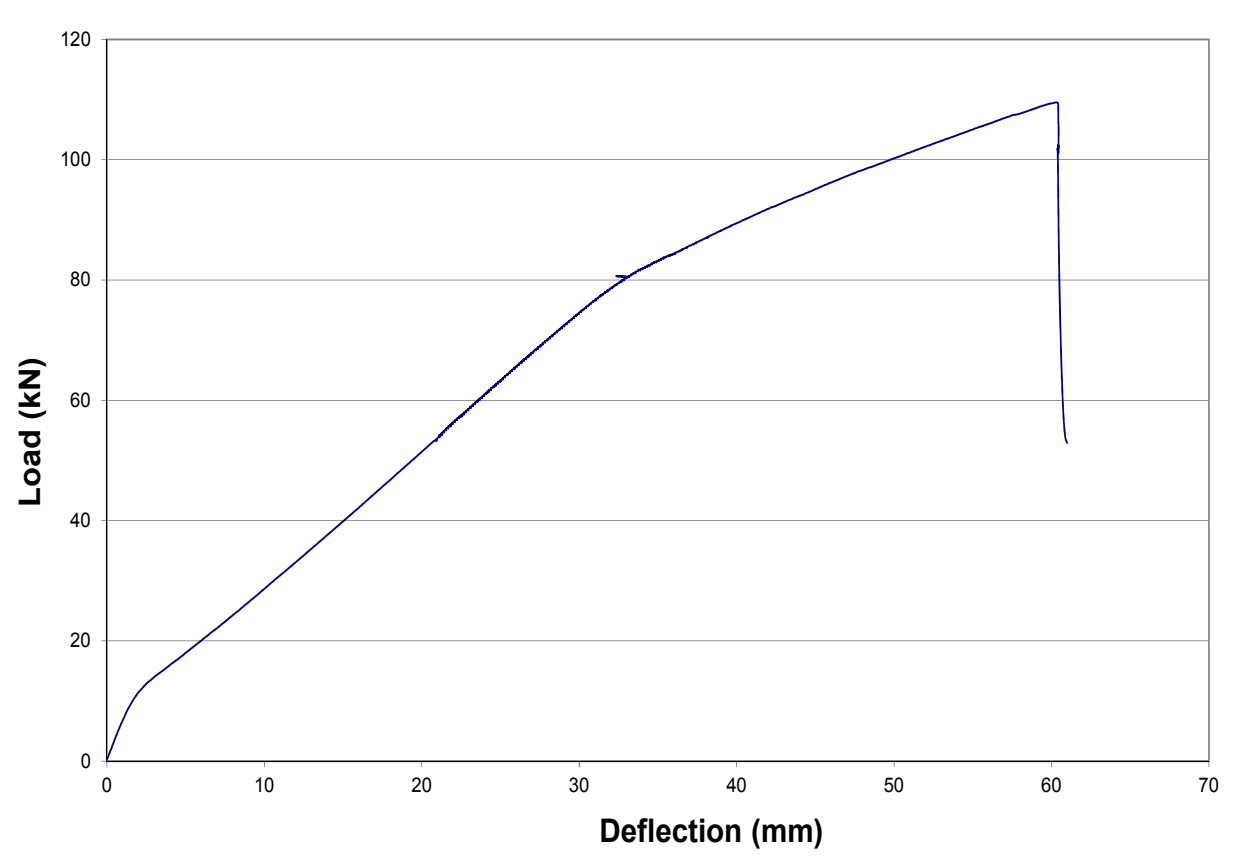

Figure 12. Load-deflection response of R2. 


\subsubsection{Rectangular Beam with CFRP and U-Wrap Anchorage (R3)}

The last beam to test in the series of rectangular beams was the beam strengthened with the same five layers of CFRP on the soffit as beam R2 while this beam had one layer of $140 \mathrm{~mm}$ wide U-shaped wraps around the web spaced at $305 \mathrm{~mm}$ on center. The beam was loaded in load control at the same rate as the other beams. Once the test procedure was started, small cracking sounds were noticed around $26.7 \mathrm{kN}$, which seemed to be a sign of premature debonding. The noises continued throughout the test, but early debonding never occurred. At a load of $89 \mathrm{kN}$, the system was switched to displacement control. The load passed the magnitude of $109.55 \mathrm{kN}$, which is the ultimate debonding load from the previous test. This was an excellent indication that the U-wraps performed as they were supposed to by inducing resistance by shear friction once the resistance by cohesion/adhesion is lost. The failure mode was initiated by the crushing of concrete cover. The beam reached an ultimate load of $120.5 \mathrm{kN}$ when the CFRP ruptured due to concrete crushing and excessive curvature at the critical section, as shown in Figure 13. This load was slightly higher than the analysis value of $116.9 \mathrm{kN}$ that was predicted to be associated with the concrete extreme compression fiber reaching a strain of 0.003 . Figure 14 shows the load-deflection relationship that was obtained from this test.

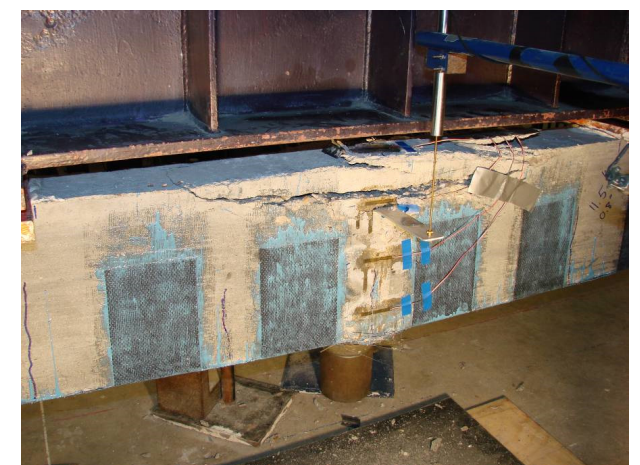

Figure 13. Beam R3 at failure.

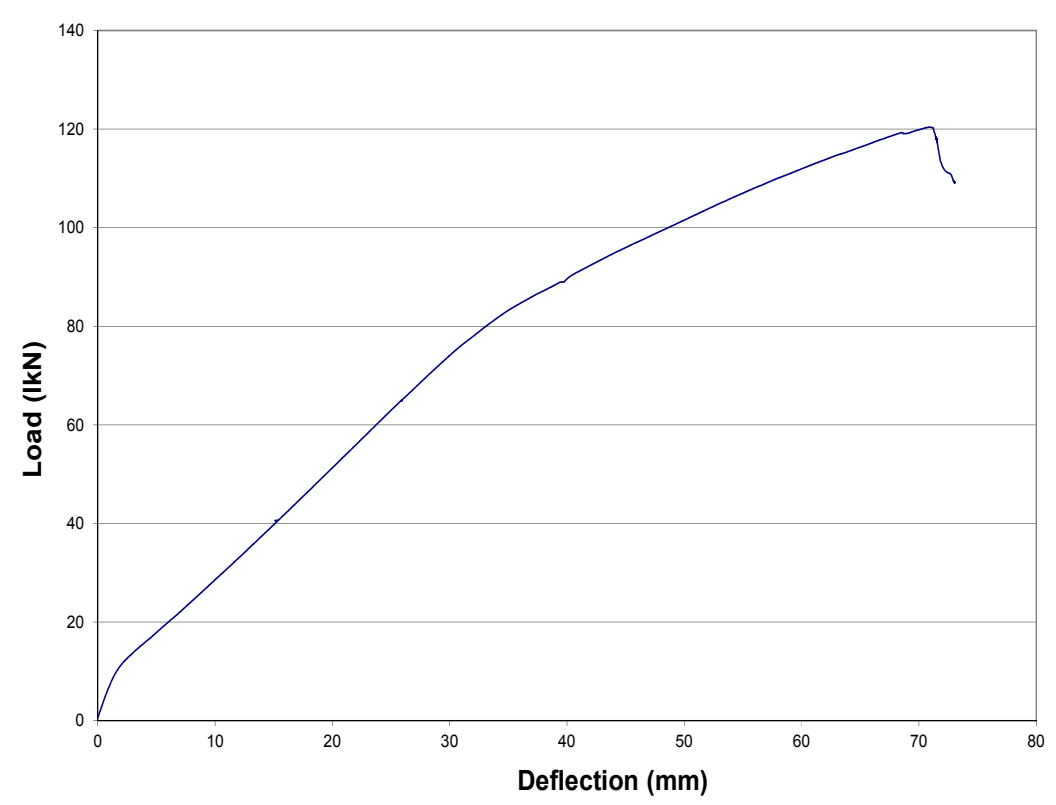

Figure 14. Load-deflection response of R3. 


\section{Numerical Analysis}

\subsection{Analysis Procedure}

The incremental deformation technique for computing the moment-curvature response of the $\mathrm{T}$ and rectangular sections is used until the section reaches either concrete crushing at the compressive extreme fiber or the FRP rupture strain inside the CFRP sheets. Then, the integration of the moment-curvature curve along the beam is implemented, to generate the load-deflection response up to the full development of the classical sectional failure modes of concrete crushing or FRP rupture. The program is also capable of tracing the strains at different locations of the beam throughout the analysis stages. The nonlinear analysis program used in this study includes confined concrete behavior and steel post-yielding stiffness and strength. To model the confinement effects, Hognestad's parabola was only used up to ultimate unconfined strength $f^{\prime}$ c followed by a linear descending branch to a stress level of $0.2 f^{\prime}$ followed by a flat plateau at that residual stress, as shown in Figure 15.

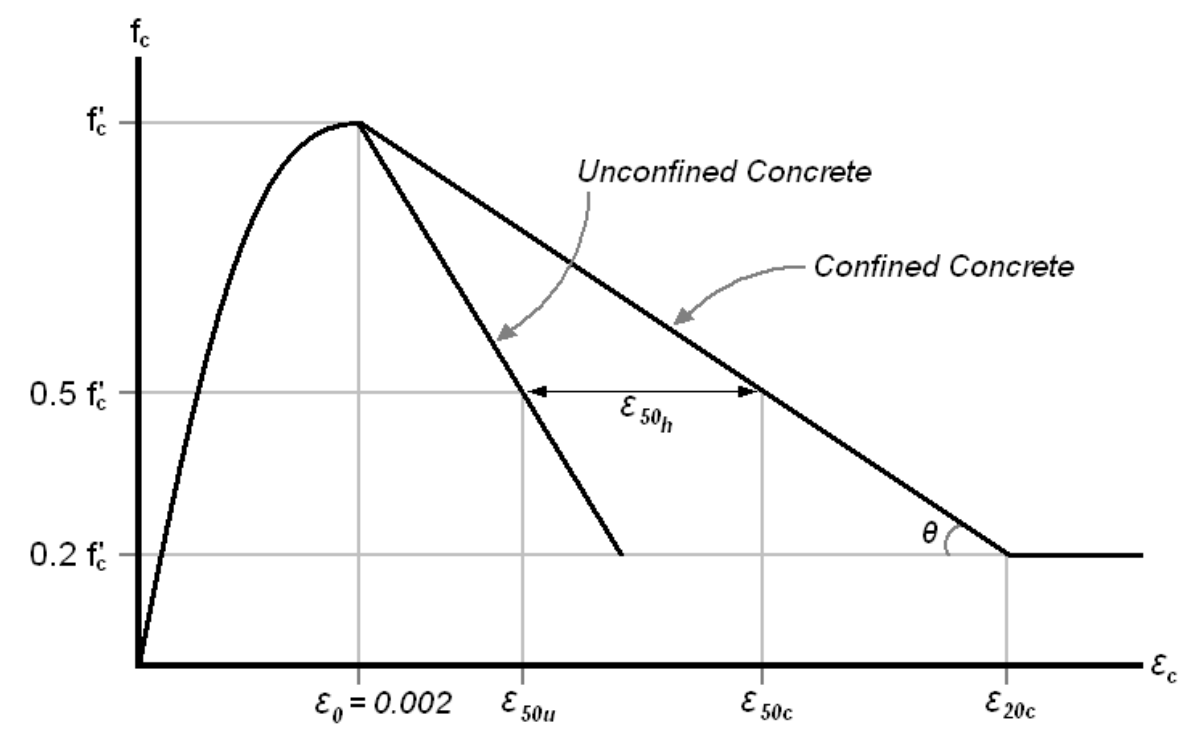

Figure 15. Confinement model for beams by Kent and Park.

The slope of the descending line was determined using the Kent and Park model, based on the level of stirrup confinement and concrete compressive strength:

$$
\begin{gathered}
E_{\mathrm{cf}}=-z f^{\prime}{ }_{\mathrm{c}} \\
z=\frac{0.5}{\varepsilon_{50 \mathrm{u}}+\varepsilon_{50 \mathrm{~h}}-\varepsilon_{0}} \\
\varepsilon_{50 \mathrm{u}}=\frac{3+\varepsilon_{0} f_{\mathrm{c}}^{\prime}}{f^{\prime}{ }_{\mathrm{c}}-1000} \\
\varepsilon_{50 \mathrm{~h}}=\frac{3}{4} \rho_{\mathrm{s}} \sqrt{\frac{b^{\prime \prime}}{s_{\mathrm{h}}}}
\end{gathered}
$$

where $E_{\mathrm{cf}}$ is the slope of the descending branch, $z$ is a slope multiplier, $\varepsilon_{50 \mathrm{u}}$ is the strain of unconfined concrete corresponding to $0.5 f^{\prime} \mathrm{c}$ and $\varepsilon_{50 \mathrm{~h}}$ is the difference between confined and unconfined concrete 
strain corresponding to $0.5 f^{\prime} \mathrm{c}, \varepsilon_{0}$ is the strain corresponding to $f^{\prime} \mathrm{c}, \rho_{\mathrm{s}}$ is the volumetric ratio of transverse reinforcement to concrete core measured to the outside of hoops, $b^{\prime \prime}$ is the width of the confined core measured to the outside of hoops, and $s \mathrm{~h}$ is the spacing of hoops. A bilinear stress-strain model was also used to introduce the post yield stiffness and strength, Figure 16.

$$
\begin{gathered}
f_{\mathrm{s}}=E_{\mathrm{s}} \varepsilon_{\mathrm{s}} \quad \text { if } \varepsilon_{\mathrm{s}} \leq \varepsilon_{\mathrm{y}} \\
f_{\mathrm{s}}=f_{\mathrm{y}}+E_{\mathrm{s}}^{\prime}\left(\varepsilon_{\mathrm{s}}-\varepsilon_{\mathrm{y}}\right) \leq f_{\mathrm{u}} \quad \text { if } \varepsilon_{\mathrm{s}}>\varepsilon_{\mathrm{y}}
\end{gathered}
$$

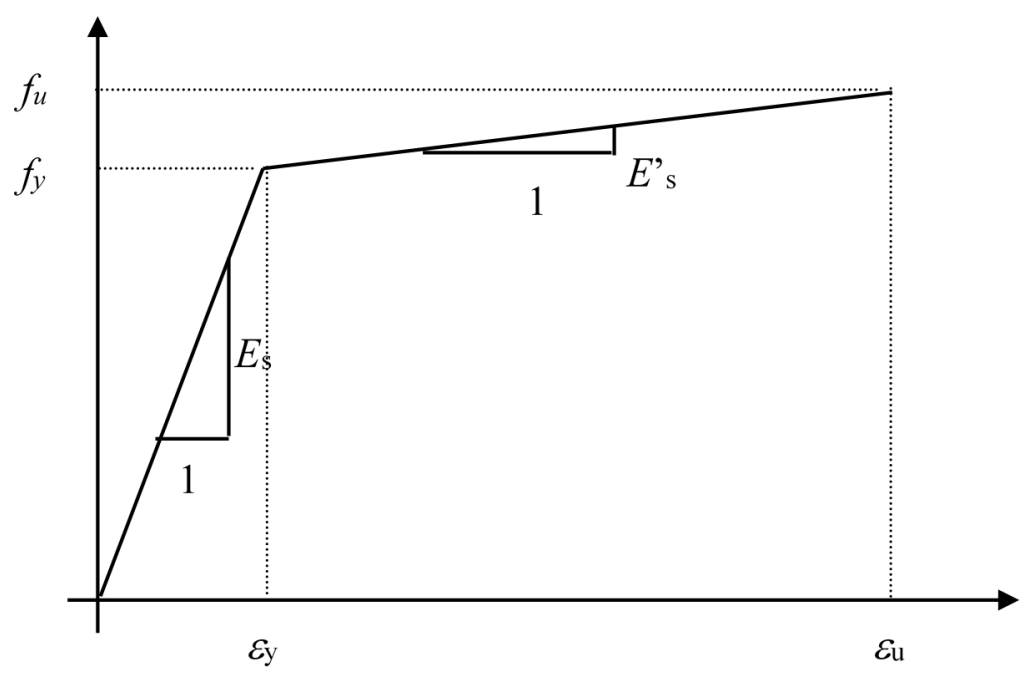

Figure 16. Stress-strain model for primary tension steel up to failure.

\subsection{Nonlinear Analysis Software}

Excel-based analysis software is used with a graphics user interface (GUI). In this software, the concrete section is divided into 1000 parallel fibers while having concrete in compression assume the model shown in Figure 15 and concrete in tension behave linear elastic up to brittle cracking. The reinforcing steel is provided as bars in their respective layers and is assumed to behave as shown in Figure 16. On the other hand, the FRP sheets are introduced at their respective depths allowing the wrapping of flexural FRP up and around the sides of the web, Figure 17, while the behavior of FRP is assumed to be linear-elastic up to brittle rupture. The software allows the analysis to be carried out for simple beams under three different loading conditions, namely three-point bending, four-point bending, and uniform loading as shown in Figure 18. The goal-seek functionality is used in Excel-based macros in Visual BASIC language to iterate for the roots of the nonlinear equations and solve for the neutral axis depth and moment-curvature point at every load level, Figure 19. 


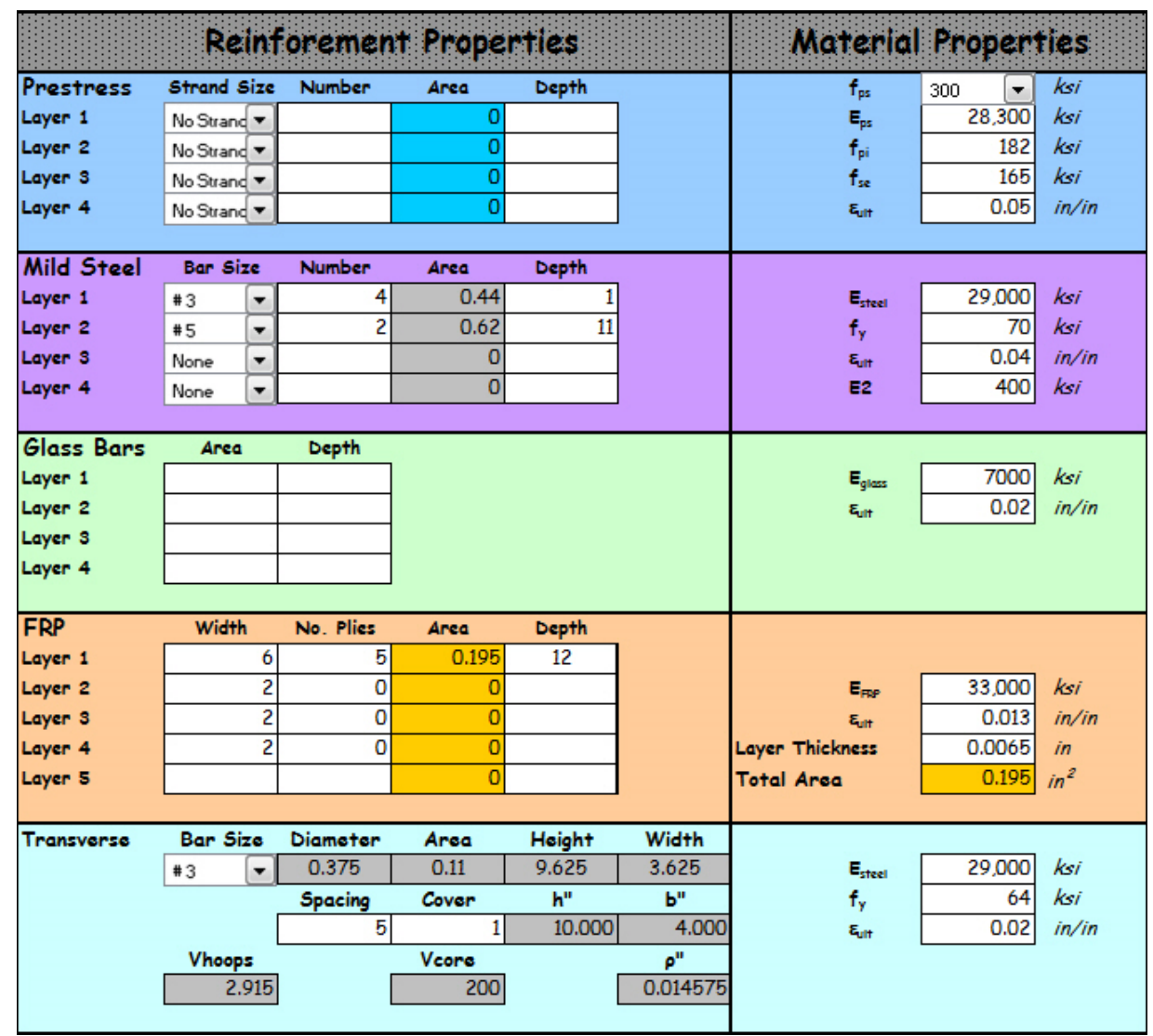

Figure 17. Graphics input interface for the various reinforcements in the section.

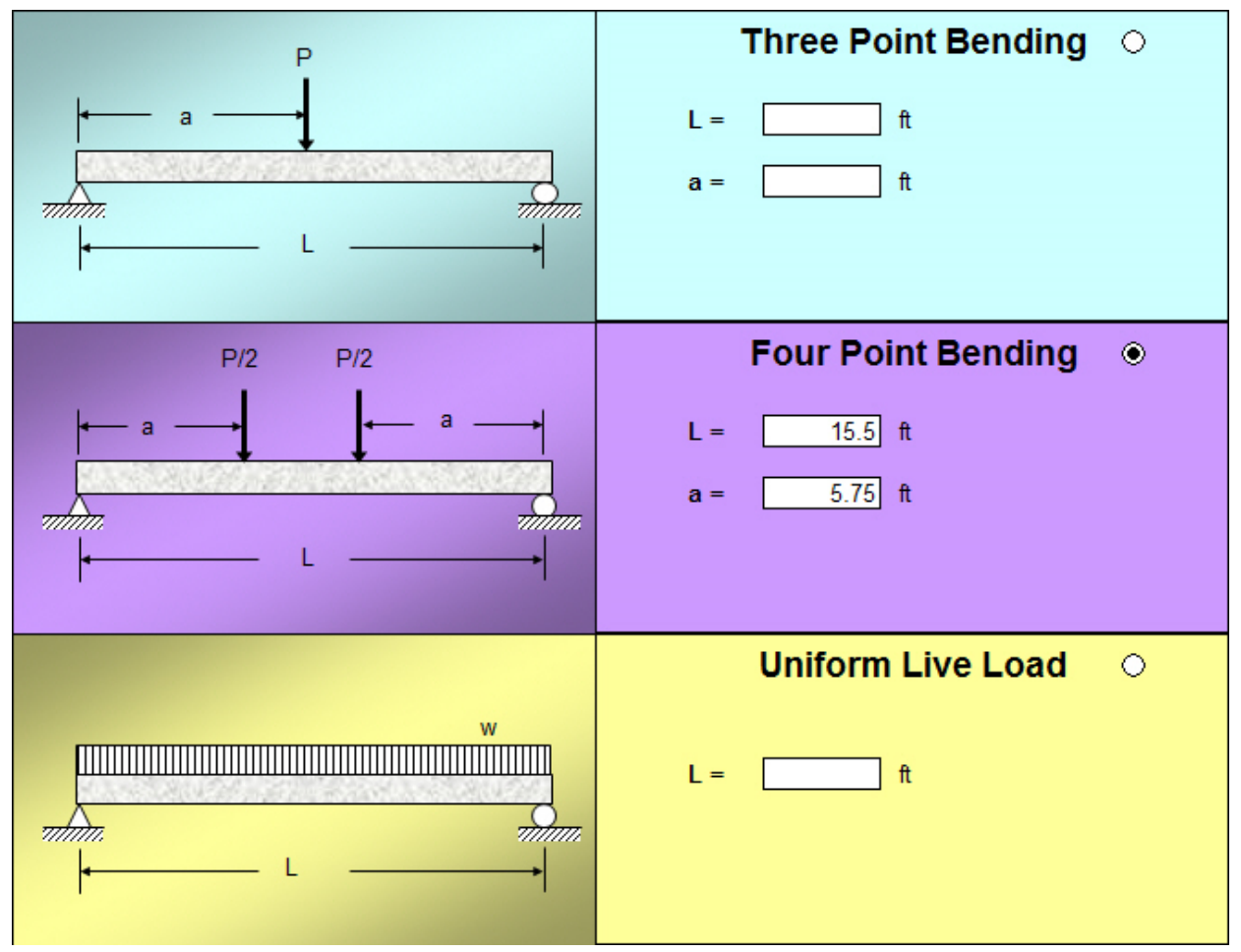

Figure 18. Graphics input interface for the various loading conditions of the beam. 


\begin{tabular}{|c|c|c|c|c|c|c|c|c|c|c|c|c|c|}
\hline Prestress & $d$ & $e$ & $\varepsilon_{1}$ & $\varepsilon_{2}$ & $\varepsilon_{3}$ & $\varepsilon_{\text {Total }}$ & $f_{\beta S}$ & $T$ & $M_{n}$ & & & & \\
\hline Layer 1 & 0.0 & 0.00 & 0.0000 & -0.00252 & 0.00000 & -0.0025 & -71 & 0.0 & 0 & & & & \\
\hline Layer 2 & 0 & 0 & 0 & 0 & 0 & -0.0025 & -71 & 0.0 & 0 & & & & \\
\hline Layer 3 & 0 & 0 & 0 & 0 & 0 & -0.0025 & -71 & 0 & 0 & \multirow{3}{*}{\multicolumn{2}{|c|}{$\begin{array}{l}\text { Reinforcement Tension } \\
\text { Concrete Tension } \\
\text { Concrete Compression }\end{array}$}} & 114.0 & kips \\
\hline Layer 4 & 0 & 0 & 0 & 0 & 0 & -0.0025 & -71 & 0 & 0 & & & 0.4 & kips \\
\hline & & & & & & & & & & & & -114.3 & kips \\
\hline Mild Steel & $d$ & $\varepsilon$ & $f_{s}$ & $T$ & $M_{n}$ & & & & & Total & & 0.0 & kips \\
\hline Layer 1 & 1 & -0.00123 & -35.6 & -15.66 & -0.31 & & & & & \multicolumn{4}{|c|}{ GoalSeek } \\
\hline Layer 2 & 11 & 0.01170 & 73.7 & 45.70 & 38.98 & & & & & \multirow{3}{*}{$\begin{array}{l}\text { Failure Mode } \\
100 \%\end{array}$} & & \multirow{2}{*}{\multicolumn{2}{|c|}{$M-\phi$}} \\
\hline Layer 3 & 0 & 0 & 0 & 0 & 0 & & & & & & FRP Rupture & & \\
\hline Layer 4 & 0 & 0 & 0 & 0 & 0 & & & & & & Complete & \multicolumn{2}{|c|}{$P-\Delta$} \\
\hline FRP Bars & $\bar{d}$ & $\varepsilon$ & $f_{g i a s s}$ & $\bar{T}$ & $M_{m}$ & & & & & \multirow{5}{*}{$\begin{array}{l}\text { Mer } \\
M n \\
\phi M n\end{array}$} & & \multirow{5}{*}{\multicolumn{2}{|c|}{$\begin{array}{l}k-f+ \\
k-f+ \\
k-f+\end{array}$}} \\
\hline Layer 1 & 0 & 0 & 0 & 0 & 0 & & & & & & 9.3 & & \\
\hline Layer 2 & 0 & 0 & 0 & 0 & 0 & & & & & & 117.3 & & \\
\hline Layer 3 & 0 & 0 & 0 & 0 & 0 & & & & & & 105.5 & & \\
\hline Layer 4 & 0 & 0 & 0 & 0 & 0 & & & & & & & & \\
\hline FRP Wraps & $\bar{d}$ & $\overline{\varepsilon_{\mathrm{i}}}$ & $\varepsilon$ & $\overline{f_{F \infty}}$ & $T$ & $M_{n}$ & $0.85 * \mathrm{M}_{\mathrm{n}}$ & & & \multirow{2}{*}{\multicolumn{2}{|c|}{$\begin{array}{l}\text { Icrements for Moment Curvature }((1000)= \\
\text { Segments for Load Deflection }(\leqslant 100)=\end{array}$}} & \multicolumn{2}{|l|}{1000} \\
\hline Layer 1 & 12 & 0.00005 & 0.01304 & 430 & 83.9 & 79 & 67 & & & & & \multicolumn{2}{|l|}{50} \\
\hline Layer 2 & 0 & 0.00000 & 0 & 0 & 0.0 & 0 & 0 & & & & & & \\
\hline Layer 3 & 0 & 0.00000 & 0 & 0 & 0.0 & 0 & 0 & & & & & & \\
\hline Layer 4 & 0 & 0.00000 & 0 & 0 & 0.0 & 0 & 0 & & & & & & \\
\hline Layer 5 & 0 & 0.00000 & 0 & 0 & 0.0 & 0 & 0 & & & & & & \\
\hline
\end{tabular}

Figure 19. Run and output interface for the nonlinear beam analysis software.

\subsection{Comparison with Beam Responses}

The analysis procedure described above is used to compare the numerical response of the three $\mathrm{T}$ beams and the three rectangular beams to their corresponding experimental response curves. Figure 20 presents the comparison for the control $\mathrm{T}$ beam. The numerical and experimental curves are seen to match very closely up to steel yielding. After that, strain hardening was evident in both curves that showed reasonably close correspondence until failure at a load of $70.75 \mathrm{kN}$ experimentally having a corresponding deflection of $160 \mathrm{~mm}$. On the other hand, the analysis shows a failure load of $67.42 \mathrm{kN}$ at a deflection of $244 \mathrm{~mm}$ indicating a shallower strain hardening response from the bilinear model. Figure 21 shows the comparison for the control rectangular beam. The numerical and experimental curves are seen to match very closely up to steel yielding as well. After that, strain hardening was also evident in both curves that showed reasonably close correspondence until failure at a load of $54.71 \mathrm{kN}$ experimentally having a corresponding deflection of $79 \mathrm{~mm}$. The analysis gives a failure load of $58.4 \mathrm{kN}$ at a deflection of $284 \mathrm{~mm}$ indicating a shallower strain hardening response from the bilinear model as well. Figure 22 presents the numerical and experimental comparison for beam T2 with flexural CFRP only. The two curves are seen to be reasonably close until steel yielding. After that, they appear to be exactly matching up to the premature debonding failure that takes place at a load of $113.74 \mathrm{kN}$ with a corresponding deflection of $51 \mathrm{~mm}$. On the other hand, the fully developed FRP rupture failure mode is indicated numerically at a load of $173.42 \mathrm{kN}$ with a corresponding deflection of $103 \mathrm{~mm}$. The debonding failure load level is estimated to take place at $105.91 \mathrm{kN}$ based on Teng et al. model [10] with a debonding strain of 0.00572 . This appears to be conservative compared with the experimental finding. Figure 23 presents the numerical and experimental comparison of the response of beam R2 with flexural CFRP only. It is evident that the two curves are very closely matching up to the experimental debonding failure load which takes place at $109.55 \mathrm{kN}$ corresponding to $60.3 \mathrm{~mm}$ deflection. On the other hand, the numerical failure load is predicted to take place at $116.93 \mathrm{kN}$ corresponding to $67.7 \mathrm{~mm}$ deflection with concrete crushing taking place at mid-span. The debonding failure load level is estimated to take place 
at $102.84 \mathrm{kN}$ based on Teng et al. model [10] with a debonding strain of 0.00572 . This appears to be slightly conservative compared with the experimental finding. Figure 24 shows the comparison of the numerical and experimental curves for beam T3 with U-wrap anchorage. It is evident that the two curves are close to each other throughout the range of loading. The experimental ultimate load in this case was increased from $113.74 \mathrm{kN}$ for beam T2 to $148.66 \mathrm{kN}$ in case of beam T3 with an FRP rupture failure mode at mid span. Even though the failure mode of beam T3 is FRP rupture, it failed at a load of $148.66 \mathrm{kN}$ corresponding to a deflection of $79.26 \mathrm{~mm}$, which is still lower than the numerical prediction of $173.42 \mathrm{kN}$ with the same failure mode of FRP rupture. This is attributed to some bond slip that is expected to have taken place after the flexural CFRP debonded then was held against full separation by the U-wraps. It is very interesting to note that the moment capacity of the beam using the reduction factor $\left(\psi_{\mathrm{f}}=0.85\right)$ implemented by the ACI 440.2R-08 [17] and applied to the contribution of the CFRP, as in Equation (5.87) of Rasheed (2014) [18], yields a failure load of $150.13 \mathrm{kN}$ which is extremely close to the actual failure load of $148.66 \mathrm{kN}$. This beam test and calculation confirms the importance of using the FRP reduction factor $\psi_{\mathrm{f}}$ in determining the moment capacity for design.

Figure 25 presents the comparison of the numerical and experimental curves for beam R3 with U-wrap anchorage. It can be seen from that comparison that the two curves are in excellent agreement all the way to failure. The tested beam R3 failed at a load of $120.47 \mathrm{kN}$ corresponding to a deflection of $70.4 \mathrm{~mm}$. This load was indicated to take place at mid-span concrete crushing and had passed the debonding failure load of beam R2, which was $109.55 \mathrm{kN}$. On the other hand, the failure load of beam R3 was very close to that numerically predicted at concrete crushing to be $116.93 \mathrm{kN}$ corresponding to a deflection of $67.7 \mathrm{~mm}$, which indicates that the anchored CFRP accomplished the classical flexural capacity of the rectangular beam R3.

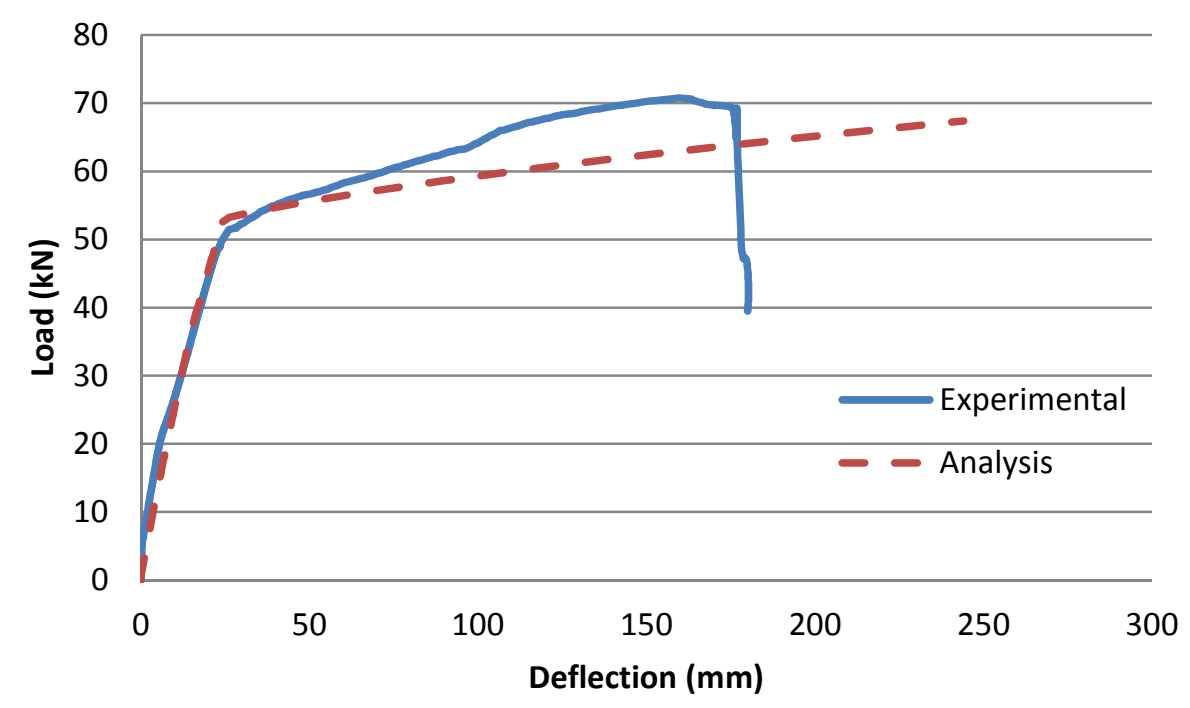

Figure 20. Comparison of test and analysis response of $\mathrm{T} 1$. 


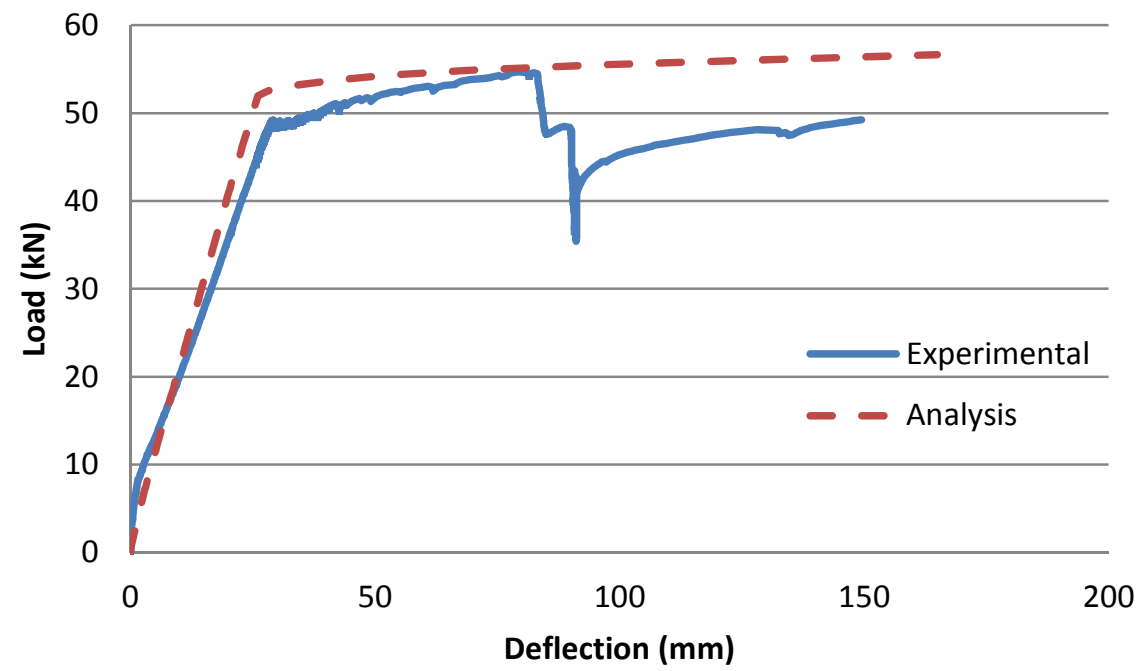

Figure 21. Comparison of test and analysis response of R1.

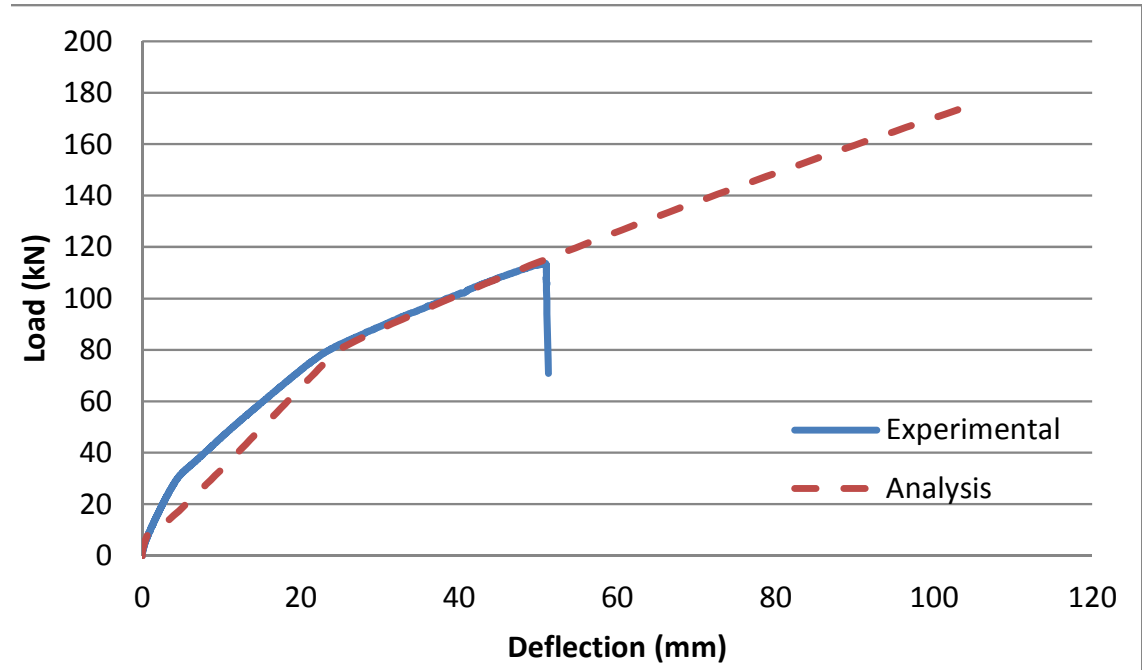

Figure 22. Comparison of test and analysis response of T2.

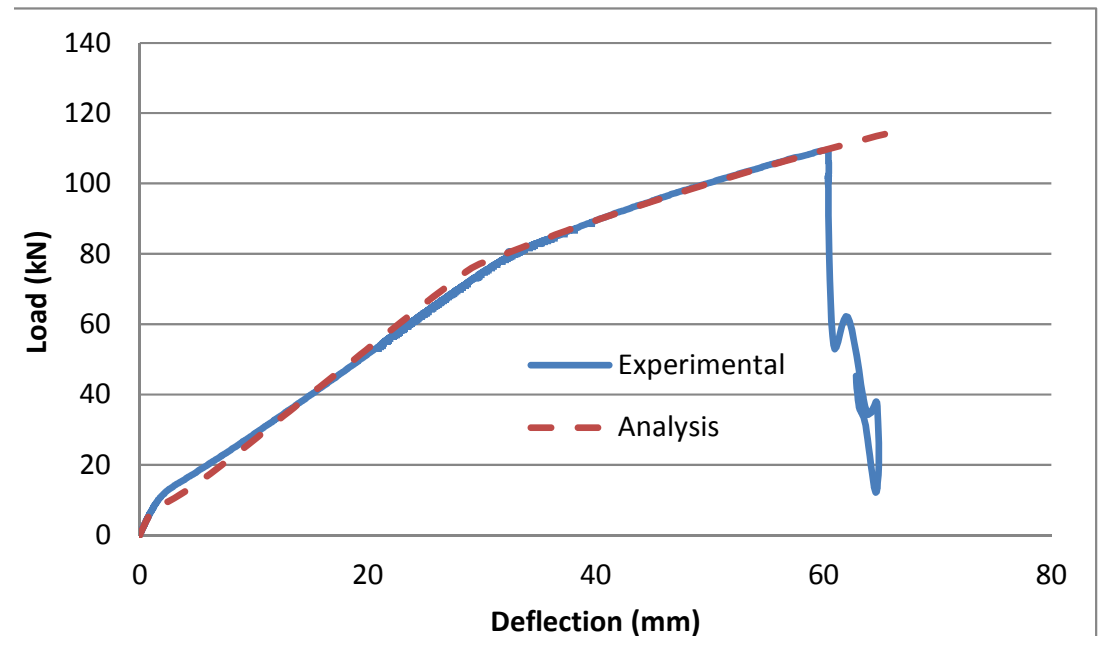

Figure 23. Comparison of test and analysis response of R2. 


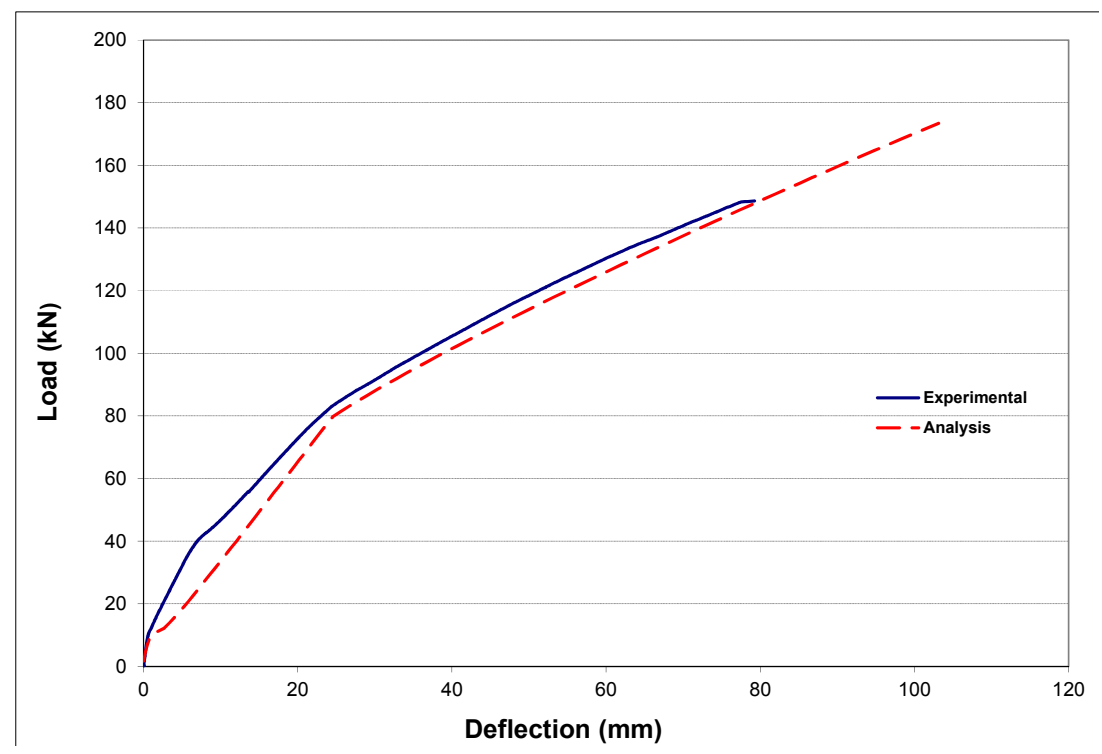

Figure 24. Comparison of test and analysis response of T3.

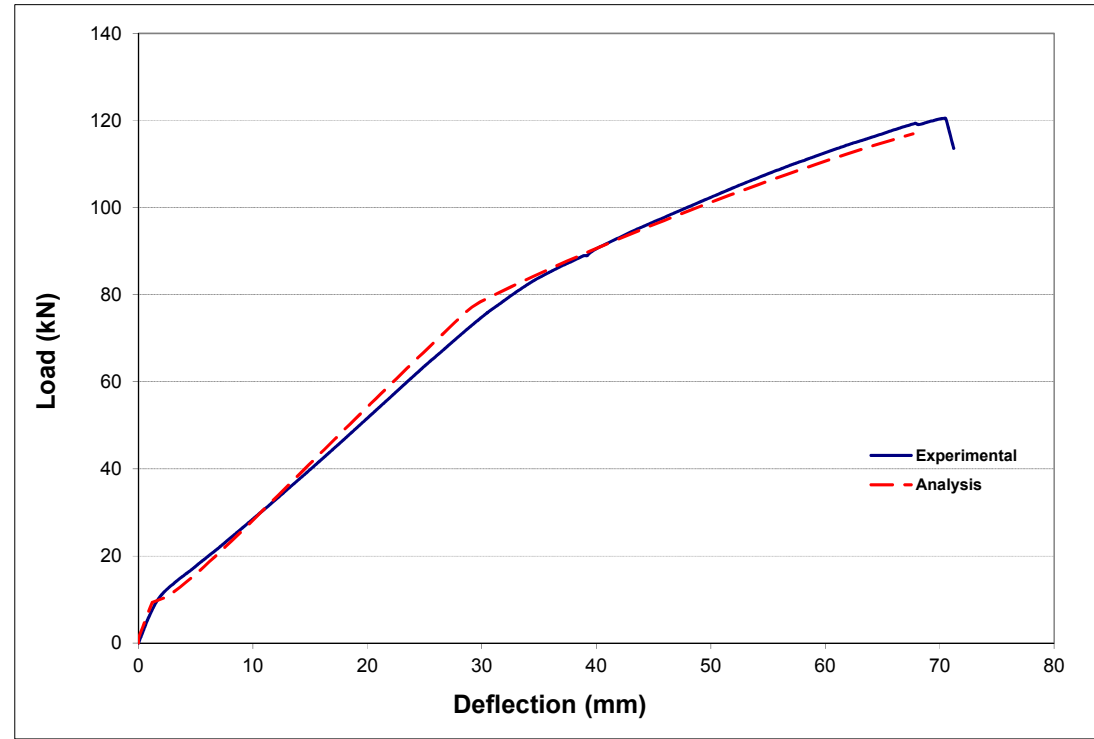

Figure 25. Comparison of test and analysis response of R3.

\section{Anchorage Design}

\subsection{Proposed Anchorage Design Procedure}

To propose a design procedure that can be used to accomplish the same results obtained in this experimental study, the ACI 318-14 [19] provisions on shear friction has been adapted to yield a simplified design model. This model computes the maximum possible tensile force in the FRP at mid span corresponding to the classical sectional failure mode of FRP rupture or concrete crushing. This force needs to be developed along the FRP shear span by furnishing distributed FRP U-wrap clamps across the debonding plane, Figure 26. Accordingly, the transverse FRP area required along the shear span is that producing enough tension to control the shear friction. The proposed design procedure is summarized in the following steps: 
1. Compute the maximum possible FRP tensile force that needs to be developed at the level of classical sectional failure moment:

$$
\begin{gathered}
T_{\mathrm{f}}=E_{\mathrm{f}} A_{\mathrm{f}} \varepsilon_{\mathrm{fu}} \text { (FRP Rupture) } \\
T_{\mathrm{f}}=E_{\mathrm{f}} A_{\mathrm{f}}\left[0.003\left(\frac{d_{\mathrm{f}}}{c}-1\right)-\varepsilon_{\mathrm{bi}}\right] \text { (Concrete Crushing) }
\end{gathered}
$$

2. Compute the horizontal shear force per unit length of shear span:

$$
V_{\mathrm{sf}}=\frac{T_{\mathrm{f}}}{L_{\mathrm{af}}}
$$

where $V_{\text {sf }}$ is the horizontal shear friction force per unit length of the FRP shear span, and $L_{\text {af }}$ is the FRP shear span.

3. Compute the clamping tension force per unit length in the transverse FRP direction using the shear friction expression:

$$
V_{\mathrm{sf}}=\mu T_{\mathrm{sf}} \stackrel{\text { yields }}{\longrightarrow} T_{\mathrm{sf}}=\frac{V_{\mathrm{sf}}}{\mu}
$$

4. Compute the clamping tension force per unit length in the transverse FRP direction. ACI 440.2R-08 [17] limits the effective FRP transverse strain $\varepsilon_{\mathrm{fe}}$ to less than 0.004 . In this model, $\varepsilon_{\mathrm{fe}}=0.003$ is assumed:

$$
T_{\mathrm{sf}}=\phi A_{\mathrm{vf}} E_{\mathrm{f}} \varepsilon_{\mathrm{fe}} \stackrel{\text { yields }}{\longrightarrow} A_{\mathrm{vf}}=\frac{T_{\mathrm{sf}}}{0.85 E_{\mathrm{f}}(0.003)}=392.2 \frac{T_{\mathrm{sf}}}{E_{\mathrm{f}}}
$$

5. Compute the width and the number of layers for the transverse FRP:

$$
A_{\mathrm{vf}}=2 n t_{\mathrm{f}} w_{\mathrm{f}} \stackrel{\text { yields }}{\longrightarrow} w_{\mathrm{f}}=196.1 \frac{T_{\mathrm{sf}}}{n E_{\mathrm{f}} t_{\mathrm{f}}}
$$
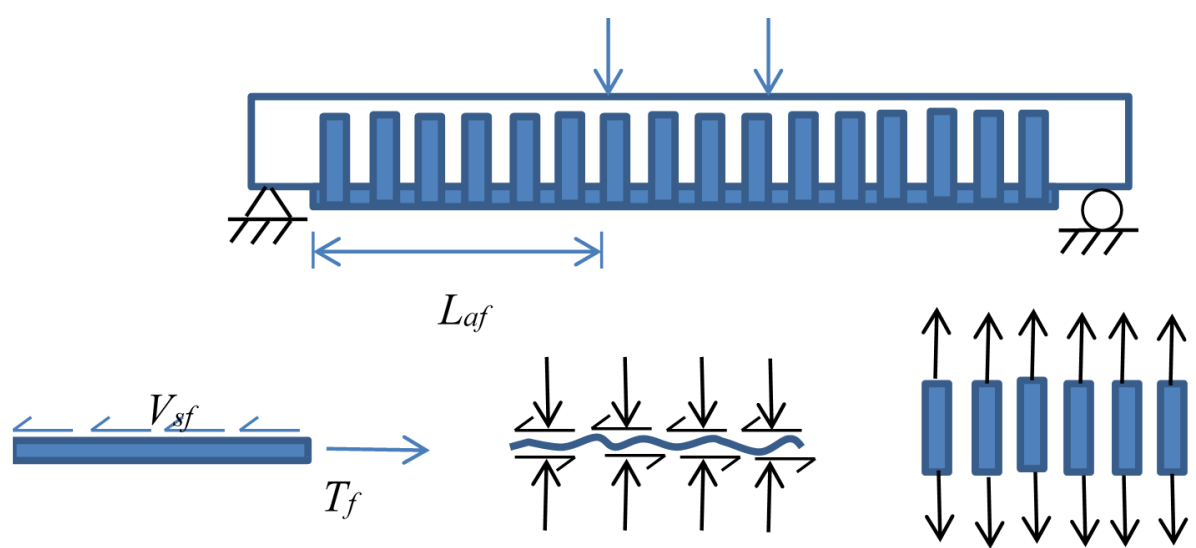

Figure 26. Schematic showing the shear friction mechanism in stretching the transverse FRP.

\subsection{Anchorage Design Details}

The following are the design calculations for the anchors used with T3 and R3 beams: 
5.2.1. Beam T3: FRP Rupture Failure Mode

$$
\begin{gathered}
T_{\mathrm{f}}=227.527 \times 5 \times 152.4 \times 0.165 \times 0.0129=369.03 \mathrm{kN} \\
V_{\mathrm{sf}}=\frac{369.03}{1.676}=220.2 \mathrm{kN} / \mathrm{m} \\
T_{\mathrm{sf}}=\frac{220.2}{1.4}=157.3 \mathrm{kN} / \mathrm{m} \\
w_{\mathrm{f}}=196.1 \frac{157.3 \mathrm{kN} / \mathrm{m}}{2 \times 227.527 \times 0.165}=410.8 \mathrm{~mm} / \mathrm{m}
\end{gathered}
$$

Use 2 layers of $127 \mathrm{~mm}$ wide U-wraps at a spacing of $305 \mathrm{~mm}$ on center $(416 \mathrm{~mm} / \mathrm{m})$.

\subsubsection{Beam R3: Concrete Crushing Failure Mode}

From force equilibrium, $\mathrm{c}=102 \mathrm{~mm}$.

$$
\begin{gathered}
T_{\mathrm{f}}=227.527 \times 5 \times 152.4 \times 0.165 \times\left[0.003 \times\left(\frac{305}{102}-1\right)-0\right]=170.8 \mathrm{kN} \\
V_{\mathrm{sf}}=\frac{170.8}{1.676}=101.9 \mathrm{kN} / \mathrm{m} \\
T_{\mathrm{sf}}=\frac{101.9}{1.4}=72.8 \mathrm{kN} / \mathrm{m} \\
w_{f}=196.1 \frac{72.8 \mathrm{kN} / \mathrm{m}}{1 \times 227.527 \times 0.165}=380 \mathrm{~mm} / \mathrm{m}
\end{gathered}
$$

Use 1 layer of $140 \mathrm{~mm}$ wide U-wraps at a spacing of $305 \mathrm{~mm}$ on center $(459 \mathrm{~mm} / \mathrm{m})$.

\section{Conclusions}

An experimental program is conducted to qualify the performance of a distributed CFRP anchorage system in controlling the deboning failure mode in $\mathrm{T}$ and rectangular beams leading to the attainment of the full flexural capacity. The results indicate the success of the technique in achieving its goals and the applicability of the Teng et al. [10] model, implemented by the ACI 440.2R-08 [17], in conservatively predicting the debonding failure. The analysis program implemented is also shown to yield excellent correspondence to the overall experimental response. A shear friction model adapted from ACI 318-14 [19] is proposed to compute the CFRP transverse U-wraps needed to effectively anchor the large number of flexural layers used. This model has yielded two different U-wrap designs that worked in achieving the classical sectional failure for both the $\mathrm{T}$ and rectangular beams. This study further confirmed the importance of using the FRP reduction factor $\psi_{\mathrm{f}}$ in determining the ultimate moment capacity for design.

\section{Acknowledgments}

The authors would like to first acknowledge the help of the research technologist Ryan Benteman of the department of Civil Engineering at Kansas State University. Thanks are also extended to Harris 
Rebar of Kansas City, MO, USA for donating the steel reinforcement and to Structural Technologies of Hanover, MD, USA for providing the CFRP materials.

\section{Author Contributions}

Hayder A. Rasheed designed the experiments and performed the analyses. Brandon R. Decker built the specimens and conducted the experiments. Asad Esmaeily, Robert J. Peterman and Hani G. Melhem helped in performing the experiments and collecting the data.

\section{Conflicts of Interest}

The authors declare no conflict of interest.

\section{References}

1. Roberts, T. Approximate analysis of shear and normal stress concentrations in the adhesive layer of plated RC beams. Struct. Eng. 1989, 67, 228-233.

2. Quantrill, R.; Hollaway, L.; Thorne, A. Predictions of the maximum plate end stresses of FRP strengthened beams: Part II. Mag. Concr. Res. 1996, 48, 343-351.

3. Täljsten, B. Strengthening of beams by plate bonding. J. Mater. Civ. Eng. 1997, 9, 206-212.

4. Malek, A.; Saadatmanesh, H.; Ehsani, M. Prediction of failure load of R/C beams strengthened with FRP plate due to stress concentration at the plate end. ACI Struct. J. 1998, 95, 142-152.

5. El-Mihilmy, M.; Tedesco, J. Prediction of anchorage failure for reinforced concrete beams strengthened with fiber-reinforced polymer plates. ACI Struct. J. 2001, 98, 301-314.

6. Rasheed, H.A.; Perviaz, S. Bond slip analysis of FRP strengthened beams. J. Eng. Mech. 2002, 128, 78-86.

7. Rasheed, H.A.; Larson, K.H.; Nayyeri Amiri, S. Analytical Solution of Interface Shear Stresses in Externally Bonded FRP-Strengthened Concrete Beams. J. Eng. Mech. 2013, 139, 18-28.

8. Ross, C.; Jerome, D.; Tedesco, J.; Hughes, M. Strengthening of reinforced concrete beams with externally bonded composite laminates. ACI Struct. J. 1999, 96, 212-220.

9. Fanning, P.; Kelly, O. Ultimate response of RC beams strengthened with CFRP plates. J. Compos. Construct. 2001, 5, 122-127.

10. Teng, J.G.; Smith, S.T.; Yao, J.; Chen, J.F. Intermediate crack-induced debonding in RC beams and slabs. Construct. Build. Mater. 2003, 17, 447-462.

11. Chahrour, A.; Soudki, K. Flexural response of reinforced concrete beams strengthened with end-anchored partially bonded carbon fiber-reinforced polymer strips. J. Compos. Construct. 2005, 9, 170-177.

12. Ceroni, F.; Pecce, M.; Matthys, S.; Taerwe, L. Debonding strength and anchorage devices for reinforced concrete elements strengthened with FRP sheets. Compos. B Eng. 2008, 39, 429-441.

13. Rasheed, H.A.; Nassajy, M.; Al-Subaie, S.; Abrishamchian, S.M.; Al-Tamimi, A. Suppressing Delamination Failure Mode in Concrete Beams Strengthened with Short CFRP Laminates. Mech. Adv. Mater. Struct. 2011, 18, 194-200. 
14. Al-Tamimi, A.K.; Hawileh, R.; Abdalla, J.; Rasheed, H.A. Effects of Ratio of CFRP Plate Length to Shear Span and End Anchorage on Flexural Behavior of SCC R/C Beams. ASCE J. Compos. Construct. 2011, 15, 908-919.

15. Grelle, S.V.; Sneed, L.H. Review of Anchorage Systems for Externally-Bonded FRP Laminates. Int. J. Concr. Struct. Mater. 2013, 7, 17-33.

16. Kalfat, R.; Al-Mahaidi, R.; Smith, S.T. Anchorage devices used to improve the performance of reinforced concrete beams retrofitted with FRP composites: State-of-the-art review. ASCE J. Compos. Construct. 2013, 17, 14-33.

17. Guide for the Design and Construction of Externally Bonded FRP Systems for Strengthening Concrete Structures; ACI Committee 440.2R-08; American Concrete Institute: Farmington Hills, MI, USA, 2008.

18. Rasheed, H.A. Strengthening Design of Reinforced Concrete with FRP; CRC Press: Boca Raton, FL, USA, 2014.

19. Building Code Requirements for Structural Concrete and Commentary; ACI Committee 318; American Concrete Institute: Farmington Hills, MI, USA, 2014.

(C) 2015 by the authors; licensee MDPI, Basel, Switzerland. This article is an open access article distributed under the terms and conditions of the Creative Commons Attribution license (http://creativecommons.org/licenses/by/4.0/). 